\title{
Control of the surface electron-beam alloying process by vibration monitoring
}

\author{
Sergey V. Fedorov", Mikhail P. Kozochkin, and Mikhail M. Stebulyanin \\ MSTU "STANKIN", Vadkovkiy lane, 3a, Moscow 127055, Russia
}

Received: 16 October 2018 / Accepted: 11 December 2018

\begin{abstract}
The experimental results prove the ability to realize technology of chemical heat treatment of some materials by surface alloying using a wide-aperture low-energy high-current electron beam. Doped hardened layers were produced due to initiating exothermic chemical reactions between the base and the thin film covered on it. Nevertheless, it is quite difficult to control the process of surface electron-beam alloying due to the significant variation in the parameters of the microsecond electron beam pulse and the instability of its interaction with the processed material. It leads to significant random changes that occur spontaneously, regardless of the control system. In this situation, it is proposed to use the method based on monitoring of oscillations and acoustic emission, which has long proved to be an effective tool in the study of phase transformations and plastic deformation. The appearance of a process with high vibroacoustic activity under irradiation of plates made of pre-nitrated steel $08 \mathrm{Cr} 17 \mathrm{Ti}$ with a deposited film $\mathrm{Nb}_{70} \mathrm{Hf}_{22} \mathrm{Ti}_{8}$ in the range of $11-22 \mathrm{kHz} 10 \mathrm{~ms}$ after the electronic pulse was experimentally shown on this background. The source of this vibroacoustic signal is a change in the microstructure of the alloy, including the appearance of a martensitic component in the near-surface layer of the sample caused by the formation of nitride based on niobium. Tracking changes in the effective value of the vibroacoustic signal allow choosing the rational modes of irradiation with electron-beam surface alloying, involving the supply of maximum power, limited by the possibility of evaporation of the film with alloying components.
\end{abstract}

Keywords: Surface alloying / electron beam / shock compression / phase transformations / vibroacoustic signal

\section{Introduction}

Numerous studies of the processes of surface alloying of structural and instrumental materials with the help of concentrated energy flows have shown the possibility of a significant impact on their physical and mechanical properties. The experimental results demonstrated the feasibility of creating wear-resistant near-surface layers by electron-beam technology using a source of wide-aperture low-energy high-current electron beam (LEHCEB) [1]. Such layers were obtained by initiating exothermic chemical reactions between the substrate material and the film deposited on it with the formation of new phase components [2-4].

The creation of structural non-equilibrium states in the near-surface layer of the substrate material during its pulsed electron-beam alloying seems to be a promising treatment when creating near-surface wear-resistant complexes before applying a protective coating. At the same time, the management of the surface-alloying process complicates a

\footnotetext{
* e-mail: sv.fedorov@icloud.com
}

sufficiently large number of control factors, which are determined primarily by the thickness of the surface layer, into which the energy sufficient for its heat treatment (melting and partial evaporation) should be introduced. These factors include the magnitude of the charging voltage, which determines the specific energy of the beam; the thickness of the film with alloying components deposited by magnetron sputtering; the number of processing cycles; and others. Their optimization was carried out by metallographic, x-ray and spectral studies [5].

However, the instability of the electron beam parameters and the process of its interaction with the processed material lead to significant random changes that occur spontaneously, regardless of the control system. It violates the strict repeatability of the technological process of surface alloying, mainly since no single observable parameter reflects its kinetics.

When pulsed by electrons, the surface layer of the substrate with an alloying coating is subjected to pulsed heating (in fact, thermal shock) during the passage of the beam, which causes the bulk expansion of the material and the corresponding movement of the thermoelastic wave $[6,7]$. The energy of this wave will be localized mainly in the 


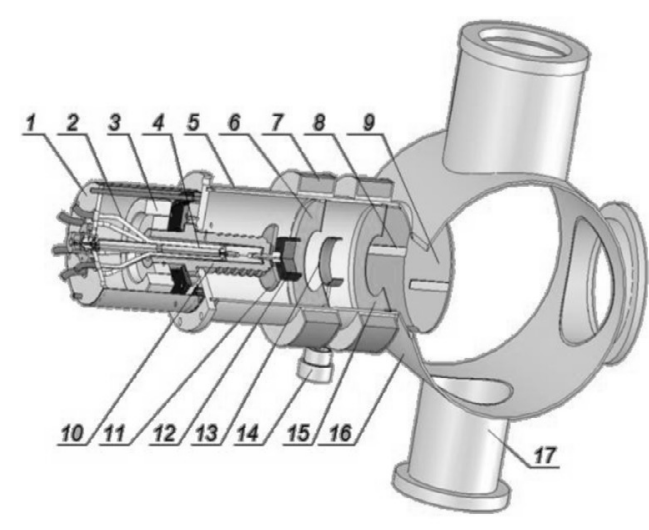

(a)

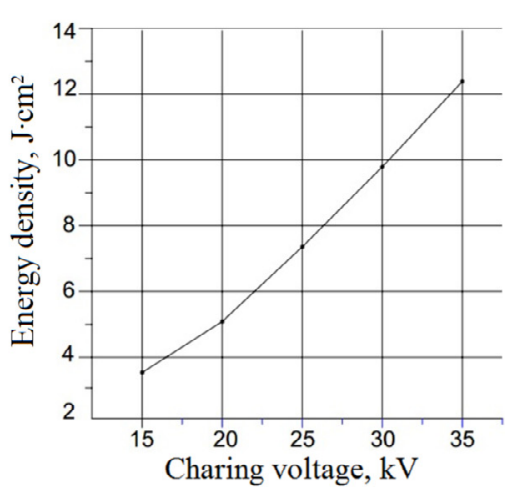

(b)

Fig. 1. Schematic description of the RITM source. (a) The electron beam gun of the source [15]. (b) The dependence of the electron beam energy density on the charging voltage of the high-voltage pulse generator.

surface layer, respectively, and the heating of the substance to high temperatures will be observed here $[8,9]$. In this case, there will be a density jump in the substance; the hidden energy of deformations and other characteristics increase, which forms a perturbing effect in the elastic system, propagating along the processed object and structural details at the speed of sound (up to $5 \times 10^{3} \mathrm{~m} / \mathrm{s}$ ). Behind the shock wave front, particles of the substance are involved in complex motion at lower rates. It activates significant changes in the crystal structure and the processes of substance transfer caused by changes in the defective structure of the material [10-12].

Phase, chemical, and structural transformations can accompany shock compression. At the same time, due to the short duration of irradiation and thermal inertia, the heating due to compression and internal friction is most likely not a physical factor that determines the behavior of the substance in such conditions. The primary role, in this case, will be played by the mechanical activation of fast physical and chemical processes in the substance, which are mainly solid phase $[13,14]$.

An equally important factor determining the microstructure and properties of the irradiated material is quasistatic thermoelastic stresses. They appear in the surface layers under pulsed heating [15]. These stresses are caused by inhomogeneous heating, and their area of action extends to hundreds of micrometers. On the surface, their value exceeds the yield strength of the material.

Experience in the creation and operation of various automated technological systems reveals the need to solve the problem of maintaining and improving the established level of reliability and efficiency $[16,17]$. These tasks can be successfully eliminated by the introduction of modern methods of diagnosis of the process $[18,19]$. In recent years, much attention is paid to vibroacoustic.

The vibroacoustic effects are one of the least studied processes observed in the interaction with metal surfaces of ion or electron beams, causing abnormally significant modification of mechanical and physicochemical properties of irradiated products. Although the share of energy spent on propagating vibrations is small (much less than 1\%), the experiments have shown that in this situation, monitoring of acoustic emission, which has proven to be a promising tool in the study of phase transformations and plastic deformation, can provide significant assistance [20-22]. Registration of vibroacoustic signal, the value of which directly depends on the power of pulses transmitted to the treated surface, allows monitoring the current performance of the synthesis process of carbide, nitride or intermetallic structures, fatigue crack propagation [23-25], and searching for optimal modes that ensure the stability of the output parameters of the process.

There are a few numbers of publications describing acoustic signals during chemical reactions and physicochemical processes in the homogeneous media [26-28]. The possibility of recording acoustic signals is explained by the fact that any chemical reaction, accompanied by the release or absorption of energy, generates elastic waves in the reaction medium. They can be detected using vibration sensors, providing reception of weak signals against their equipment noise. The appearance of acoustic signals during chemical reactions is also caused by the change in the volume of reaction products in comparison with the initial amount of components since the process of volume change is equivalent to the appearance of the density gradient $[29,30]$.

The novelty of this work is the proof of the possibility of correcting the factors of the surface hardening process by surface electron-beam doping through vibroacoustic monitoring. The research task of this work is to find connections between changes in the microstructure of the near-surface layer of steel occurring during the LEHCEB surface treatment process with changes in the parameters of the accompanying vibroacoustic signal on the example of alloying pre-nitrated ferritic sheet steel by niobium alloy.

\section{Experimental}

The surface alloying process was carried out at the RITMSP unit. This unit represents an experimental setup, produced in the Institute of High-Current Electronics (SB RAS, Tomsk, Russia). It is a combination of a source of low-energy high-current electron beams RITM (Fig. 1a) 


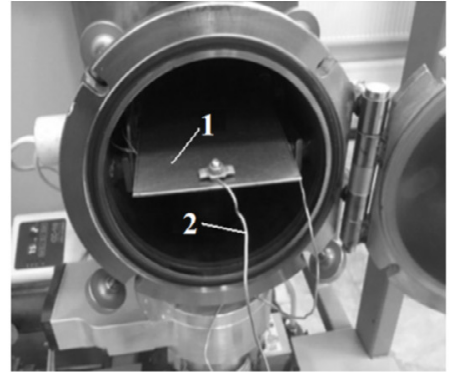

(a)

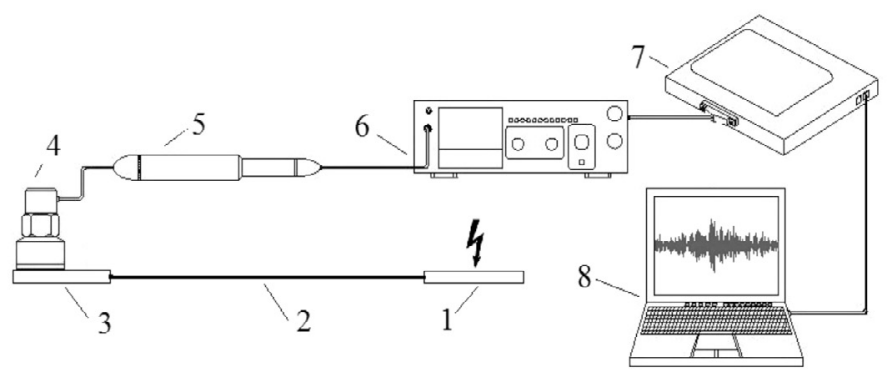

(b)

Fig. 2. Experimental setup. (a) The sample placed in the "RITM-SP" unit for surface alloying. (b) The scheme for vibroacoustic signals recording: 1-a sample; 2-wire waveguide; 3-a receiving plate; 4-a KD-35 accelerometer with a magnet (ViCont, Moscow, Russia); 5-PM-3 preamplifier Izmeritel, Rostov, Russia); 6-VSV-003 amplifier (ViCont, Moscow, Russia); 7-E440 ADC (L-Card, Moscow, Russia); 8-registering computer.

and two magnetron sputtering systems installed on a single vacuum chamber. The unit allows sputtering of films of different materials on any surface and subsequent liquidphase mixing of film and substrate materials by an intensely pulsed electron beam [31].

The source consists of a flange (1), cables (2), a Rogowski coil (3), a voltage divider (4), a gun body (5), diaphragms (6) and (15), a solenoid (7), a reverse conductor (8), a collector (9), a porcelain insulator (10), a screen (11), a cathode (12), an anode of the reflective discharge (13), an anode input (14), a vacuum working chamber (16), and a pumping outlet (17).

The generation of LEHCEB involves the emission of electrons, the formation of a beam in a plasma-filled diode, and its transport in the plasma channel. Using such a generation scheme allows obtaining a beam with a duration of about $5 \mu \mathrm{s}$, with a current density of up to $104 \mathrm{~A} / \mathrm{cm}^{2}$ at a charging voltage $15-30 \mathrm{kV}$, the value of which depends on the specific power in the beam (Fig. 1b). The area of onetime processing is about $50 \mathrm{~cm}^{2}$.

The units work table (Fig. 1a, pos.9) was replaced by a sample from a sheet of ferritic stainless steel AISI 439 (08Cr17Ti) to remove possible extraneous noise.

The choice of steel AISI 439 as a starting material was due to the high content of chromium and low carbon content, at which carbides of alloying elements practically do not form. It allows saving the chromium in a solid solution and provides high solubility of nitrogen, which will be necessary for the formation of particular nitrides during the surface alloying process. The similar alloys are used in the automotive, food and medical industries, where standards attach great importance to corrosion and wear resistance. In general, the corrosion resistance of stainless steel is a consequence of a thin oxide film formed on the surface and enriched with chromium oxide. The effectiveness of this protective film can be changed by adding alloying elements to the solid composition of the metal base $[32,33]$. Transformation of chromium into carbide can significantly reduce the corrosion resistance. A feasible approach is to replace carbon with nitrogen to eliminate chromium carbides and, at the same time, to create favorable conditions for the formation of nitrides, which can significantly increase corrosion resistance and provide a high hardness of about 60 HRC.
Before surface alloying, the steel preliminarily underwent low-temperature nitrating on a nitrating-pluscoating-type PVD unit (manufactured by MSTU "STANKIN," Moscow, Russia) with a two-stage vacuum-arc gas discharge to achieve this effect [34]. The treatment took place at a temperature of $500{ }^{\circ} \mathrm{C}$ for $60 \mathrm{~min}$, which made it possible to create a layer with a thickness of about $40 \mu \mathrm{m}$ on the surface formed by the chemical heat treatment without the appearance of chromium nitride $\mathrm{Cr}_{2} \mathrm{~N}$. It should be noted that the method of nitriding is not crucial. Good results were obtained using plasma obtained by a beam of fast neutral molecules [35]. The subsurface layer acquires a martensitic-austenitic structure. The increase in the average mass fraction of nitrogen leads to the stabilization of residual austenite.

Further, a metal coating of $\mathrm{Nb}_{70} \mathrm{Hf}_{22} \mathrm{Ti}_{8}$ alloy with a thickness of $0.15-0.2 \mu \mathrm{m}$, which was subsequently used as a material for surface alloying, was applied to some plates by magnetron sputtering. The irradiation of LEHCEB on the deposited film leads to the formation of a surface alloy and causes dissociation of iron nitrides. The released nitrogen atoms enter an exothermic chemical reaction with the coating material to form the refractory nitride phases based on $\mathrm{Nb}$ and $\mathrm{Hf}$, which are strong nitride formers. The presence of hafnium, having a greater heat of nitride formation than niobium $(406 \mathrm{~kJ} / \mathrm{mol}$ for $\mathrm{HfN}$ and $238 \mathrm{~kJ} / \mathrm{mol}$ for $\mathrm{NbN}$ ), substantially stabilizes the process.

The phase composition of the near-surface layer was monitored by X-ray diffraction. The steel samples were taken by PANalytical Empyrean Series 2 X-ray diffractometer (Malvern Panalytical B.V., Eindhoven, Holland) using $\mathrm{CuK} \alpha$ radiation and method of sliding $\left(5^{\circ} 30^{\prime}\right)$ X-ray beam because of the specificity of the studied surface layer with the large gradient of the structural parameters in depth [36]. The microstructure of the near-surface layer was explored by a transmission electron microscope JEM200CX (JEOL, Tokyo, Japan).

The plate was connected to the KD-35 accelerometer with a waveguide in the form of a copper wire with a cross section of $2.5 \mathrm{~mm}^{2}$ to register the vibroacoustic signal arising during the process. The scheme of the observation channel is shown in Figure 2b.

A feature of the unit for the registration of vibroacoustic signals in the processing zone is the use of a 


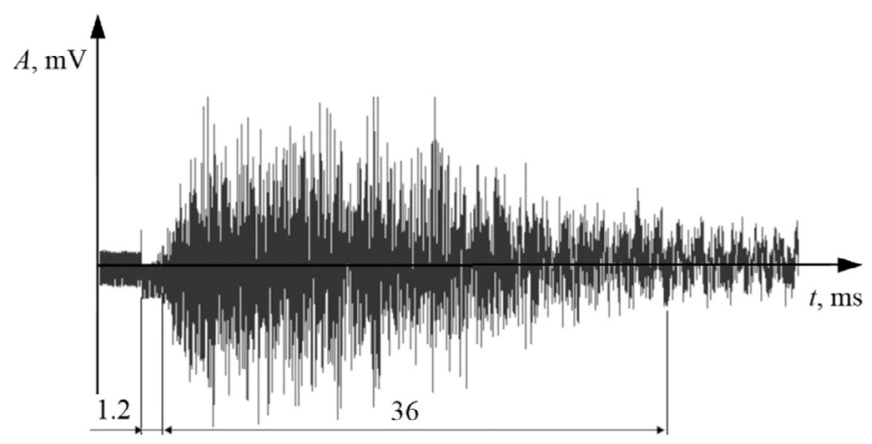

Fig. 3. An example of recording a vibroacoustic signal after the pulse: $1.2 \mathrm{~ms}$ - the time from the moment of the occurrence of electromagnetic interference to the beginning of the signal recording; $36 \mathrm{~ms}$ - the time of the presence of the main energy of the vibration signal.

waveguide in the form of a copper wire of small diameter. Preliminary tests have shown the possibility of using such thin and flexible waveguides of great length. The remoteness of the recording equipment from the "RITM-SP" unit is essential because the operation of the electron gun is accompanied by dominant electromagnetic interference. The flexibility of the waveguide is necessary for rapid replacement and movement of the test samples inside the vacuum chamber. Recording and processing of vibroacoustic information were performed by the software system "nkRecorder" (MSTU STANKIN, Moscow, Russia) [37].

The analysis of the mechanical pulse arising on the workpiece at the moment of the electron beam exposure is complicated by an extended elastic system, which includes the above-considered wire waveguide. The initial signal, passing through the elastic system, undergoes transformations in accordance with the amplitude-frequency characteristic of the observation channel [38]. With electron pulse duration of about $5 \mu$ s, the upper frequency of its spectrum can extend up to $0.3 \mathrm{MHz}$. However, the acoustic signal attenuation occurs during the passage of the wave process along the extended elastic system, which is associated with internal friction in the material and contact friction at the joints of individual parts [39]. The signal attenuation rate increases rapidly with increasing frequency, so the signal in the range up to $40 \mathrm{kHz}$ was reliably recorded on the receiving plate against the background noise. The noise interference generated by the items of the "RITM-SP" unit was located at relatively low frequencies up to $2 \mathrm{kHz}$ and was excluded from consideration.

The recorded vibroacoustic signal received time and frequency analysis to obtain information on the processes occurring on the irradiated sample. The comparison of spectra of vibration signals obtained for different time intervals from the moment of occurrence of a pulse and the comparison of the records of the effective values of the signals after filtering in different frequency bands took place. The width of the analyzed bands approximately corresponded to one octave. The analysis of amplitudes in narrower frequency ranges is characterized by a large spread due to the random variations of the pulse shape in the electron beam and the complex amplitude-frequency characteristic of an elastic system. Figure 3 shows an example of recording a signal from the accelerometer after the electronic pulse is applied.

It can be seen that the moment of supplying of the working impulse is accompanied by the appearance of electromagnetic interference, which affects the hardware of the measuring channel, generating an interference impulse $1.2 \mathrm{~ms}$ before the acoustic signal itself appears on the recording. In this case, the major part of vibration energy is present on the record for about $36 \mathrm{~ms}$. The total duration to complete attenuation is about $150 \mathrm{~ms}$. It is important to note that the accelerometer registers a signal of vibration acceleration, which increases the amplitude of the spectral components of the vibrations as the square of the frequency. It allows the better consideration of highfrequency components. The vibration acceleration was recorded in $\mathrm{mV}$ since the absolute values are bound only to the vibrations of the receiving plate and depend on the type of waveguide and its frequency characteristics. At the constancy of observation conditions for comparing the parameters of acoustic signals received in different periods and under different disturbing influences, the units of measurement do not matter.

\section{Results}

\subsection{Effect of the pulsed electron beam charging voltage on the amplitude effective value of the vibroacoustic signal}

For identifying the rational modes of irradiation and subsequent comparison of the corresponding parameters of acoustic signals, the first experiments with the steel samples without any additional treatments were conducted. The working pulses were supplied at different values of the generator charging voltage. As the parameters of the vibroacoustic signal, reflecting the kinetics of processes on the surface of the workpiece, we took the effective (mean square) amplitudes of these signals in octave bands with central frequencies of 16 and $32 \mathrm{kHz}$. Figure 4 shows the effective amplitude changes in these octaves at a charging voltage of $22 \mathrm{kV}$.

Figure 4 shows that the main part of the energy of the vibroacoustic signal in this particular case is concentrated in the area up to $20 \mathrm{~ms}$. The high-frequency component of $32 \mathrm{kHz}$ attenuates faster; its amplitude is approximately four times less than the octave of $16 \mathrm{kHz}$. The nature of changes in the effective values of the vibroacoustic signal in two octaves at a charging voltage of $16 \mathrm{kV}$ remained, but the amplitude has dropped significantly.

The processing of the results of such experiments at different charging voltages allowed obtaining the dependences of the effective values of the vibroacoustic signal in octaves of 16 and $32 \mathrm{kHz}$ on the charging voltage in the range from 16 to $25 \mathrm{kV}$ (Fig. 5).

It can be concluded from the graphs in Figure 5 that the amplitude of the vibroacoustic signal at high frequency with a charging voltage of $16-20 \mathrm{kV}$ varies little with an increase in the charging voltage. A sharp growth starts 


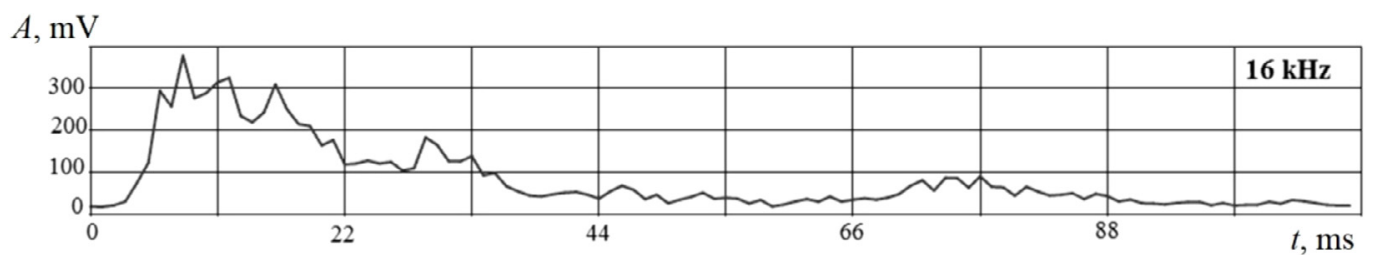

(a)

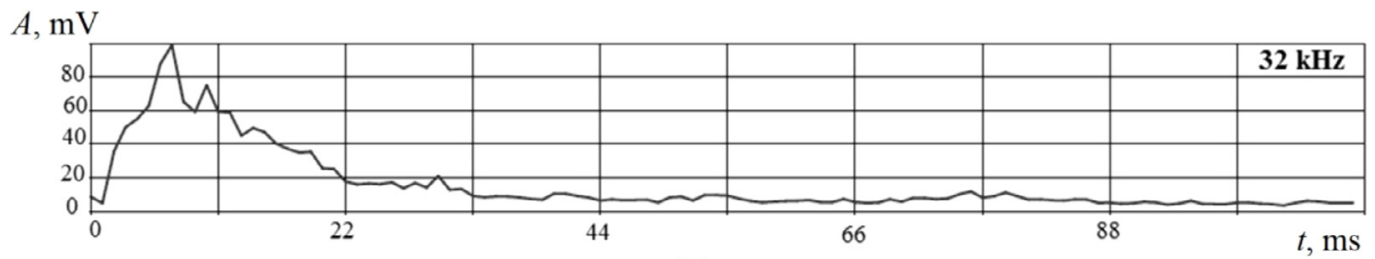

(b)

Fig. 4. The change in the effective amplitude values of the vibroacoustic signal under a working pulse to a steel plate at a charging voltage of $22 \mathrm{kV}$ in octaves: (a) $16 \mathrm{kHz}$, (b) $32 \mathrm{kHz}$.

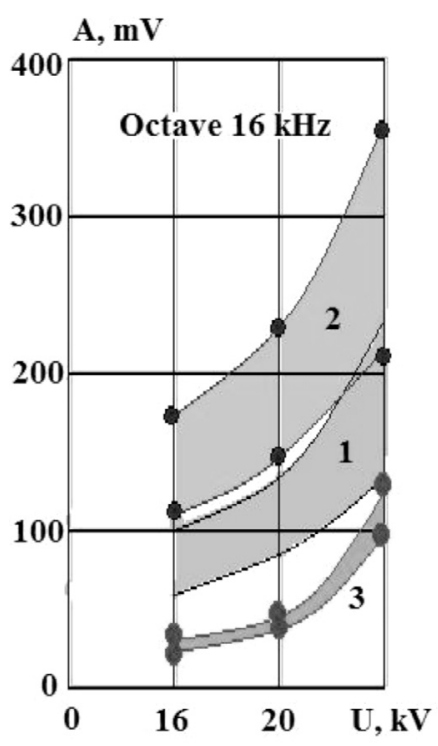

(a)

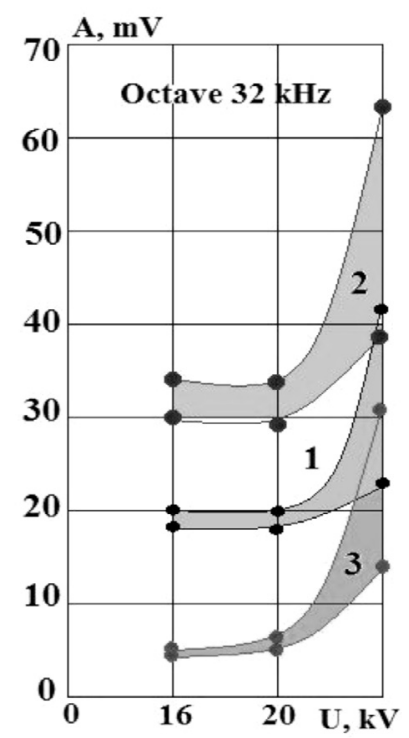

(b)

Fig. 5. The change in the effective value of the vibroacoustic signal depending on the charging voltage of the pulse: (a) in octaves of $16 \mathrm{kHz}$; (b) in octave of $32 \mathrm{kHz}$; 1-during $150 \mathrm{~ms}$; 2-for the first $50 \mathrm{~ms}$; 3 -for the second $50 \mathrm{~ms}$.

from $22 \mathrm{kV}$. Especially noticeable is the rapid increase in the amplitude of the signal during the second $50 \mathrm{~ms}$ from the moment of the pulse. For a voltage of $25 \mathrm{kV}$ in an octave of $32 \mathrm{kHz}$, the amplitude is three to six times higher than the signal at $16 \mathrm{kV}$.

A sharp increase in the amplitude of the vibroacoustic signal at high values of the charge voltage can be associated with an increase in the energy of thermal shock and with the intensification of the evaporation of the metal from the surface of the sample. Therefore, the increase in the recoil pulse is associated with the expansion of vapors. In this case, such amplification of the vibroacoustic signal occurs at a charging voltage on the capacitor of $20-22 \mathrm{kV}$. This

indication will determine the charging voltage values in the surface alloying experiments. Its excess can lead to the evaporation of most of the coating with alloying components, which in the course of these experiments will be applied to the steel samples.

\subsection{Changes in the structure and vibroacoustic signal when steel nitriding}

A ferritic (martensitic) component and an insignificant amount of chromium carbide $(\mathrm{FeCr})_{23} \mathrm{C}_{6}$ are observed in the surface structure of the original steel sample after electron beam exposure. The change in the relative intensity of the peaks indicates the formation of a rather sharp texture. The surface roughness increases.

The surface of the samples of irradiated nitrated steel 08Cr17Ti looks smoother than the samples after exposure to LEHCEB in the initial state. The austenite prevails in the microstructure with a grain size of up to several micrometer. In the body of the grain, there is an intensive release of small (up to $10 \mathrm{~nm}$ ) particles of the nitride phase, identified as $\mathrm{Fe}_{3} \mathrm{~N}$ (Fig. 6a). A small amount of chromium nitride $\mathrm{CrN}$ is also present. In some places, one can find zones of martensitic component (Fig. 6b). Here and further on the inserts are the diffraction patterns corresponding to the TEM image. The arrow points to the reflex in which the dark field image was obtained.

The comparison of vibroacoustic signals during irradiation of ordinary and nitrated steel plates showed that the nature of the response to the pulse effect varies slightly, despite a significant change in the structure of the metal in the surface layer. Figure 7 shows an example of changing the effective amplitude of the vibroacoustic signal in an octave of $16 \mathrm{kHz}$ under irradiation of pure (Fig. 7a) and nitrated (Fig. 7b) steel plates. As it can be concluded from the graphs, the irradiation of the nitrated surface does not lead to an increase in the amplitude of the vibroacoustic signal in a given octave, but a shift in the time of its occurrence is noticeable. The signal occurs approximately $5 \mathrm{~ms}$ earlier. 


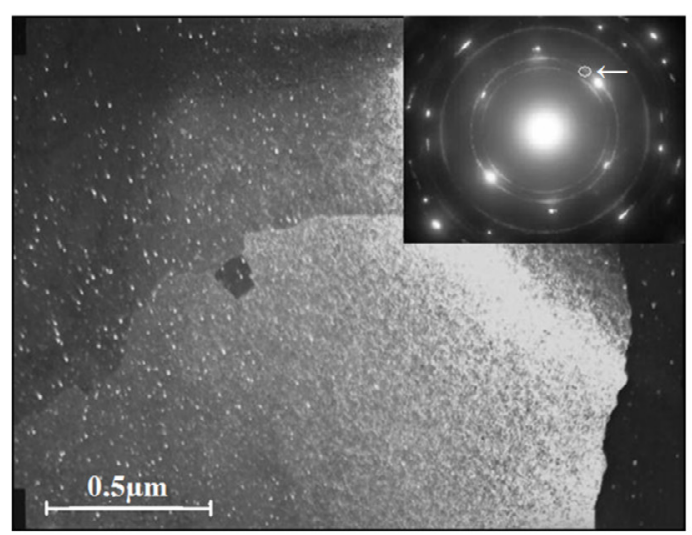

(a)

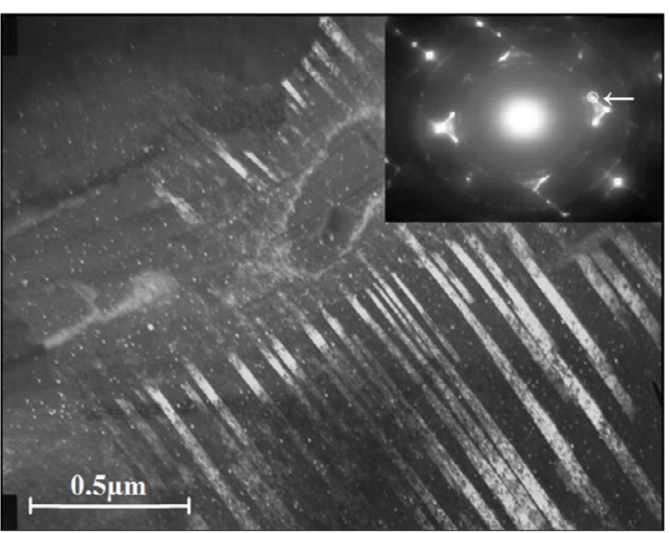

(b)

Fig. 6. TEM image of the surface layer microstructure in a sample of steel $08 \mathrm{Cr} 17 \mathrm{Ti}$, formed after ion nitriding and irradiating the LEHCEB at a charging voltage of $20 \mathrm{kV}$. (a) A dark field in the reflex of the $\mathrm{Fe}_{3} \mathrm{~N}$ phase. (b) A dark field in the reflex of martensite.

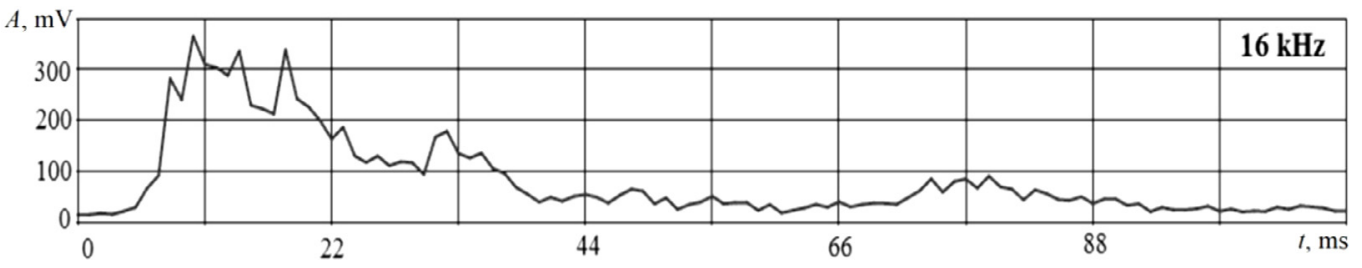

(a)

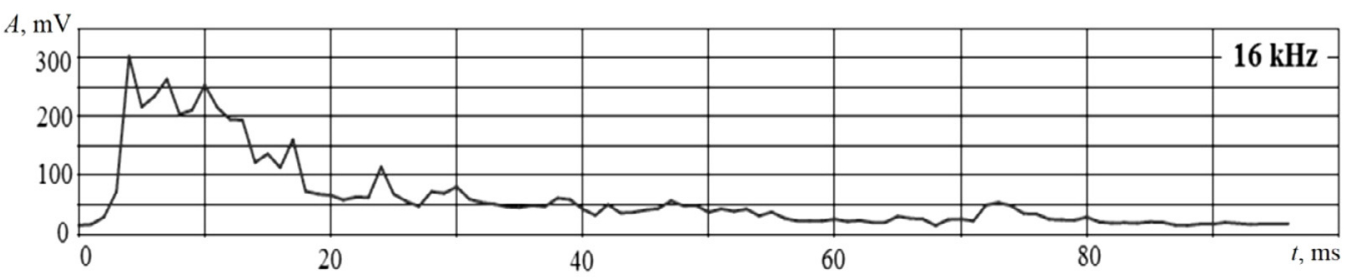

(b)

Fig. 7. The change in the effective amplitude of the vibroacoustic signal in an octave of $16 \mathrm{kHz}$ when irradiated with a pulse with a charging voltage of $22 \mathrm{kV}$ : (a) - a steel plate; (b) - a steel plate with a nitrated surface.

\subsection{Changes in the structure and character of the vibroacoustic signal during surface alloying of steel}

The next stage of the experiment was the study of the influence of changes in the microstructure of the nearsurface layer on the vibroacoustic signal, arising after the irradiation of a steel plate with a coating of a target film made of $\mathrm{Nb}_{70} \mathrm{Hf}_{22} \mathrm{Ti}_{8}$ alloy.

After irradiation of such a sample by the electron beam, mixing of materials of coating and base takes place and there starts an exothermic chemical reaction with the formation of nitride phases based on niobium and hafnium; the average content of niobium in the near-surface layer of the treated samples according to X-ray spectral analysis was approximately $0.5 \%$. Titanium contained in the film, apparently, plays the role of getter and burns out. In some experiments, the traces of high-temperature modification of titanium oxide, $\mathrm{TiO}$, was found. The consequence of the reaction of the formation of a new nitride phase is the depletion of the austenitic component by nitrogen, which under conditions of rapid cooling after pulsed heating by electrons causes a martensitic transformation.

Both the formation of nitride phases and the formation of martensite in the surface layer of the sample are accompanied by a change in volume and contribute to plastic deformation, which can be a fairly strong source of the vibroacoustic signal. The features of the effects of irradiation of such samples are inevitably displayed in the nature changes in their parameters. Figure 8 shows the graphs of the variation of the effective amplitude in octaves of 16 and $32 \mathrm{kHz}$ when the coated steel sample is irradiated.

If the graphs shown in Figures 8a and 4a are compared, the analogy can be traced only during the first $10 \mathrm{~ms}$. A decrease in the amplitude of the vibroacoustic signal appears after the 7 th $\mathrm{ms}$, as in previous experiments, but 
A, $\mathrm{mV}$

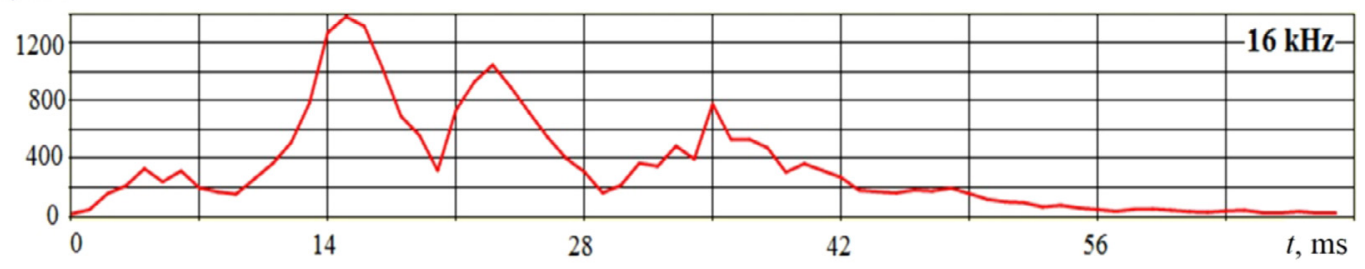

(a)

A, $\mathrm{mV}$

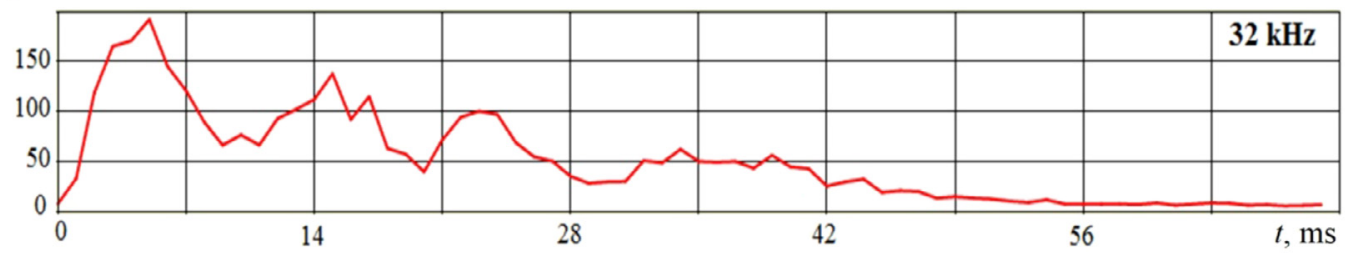

(b)

Fig. 8. The change in the effective amplitudes of the vibroacoustic signal when a working pulse is applied to a steel plate with a layer of $\mathrm{Nb}_{70} \mathrm{Hf}_{22} \mathrm{Ti}_{8}$ film at a charging voltage of $22 \mathrm{kV}$ in octaves: (a) $16 \mathrm{kHz}$, (b) $32 \mathrm{kHz}$.

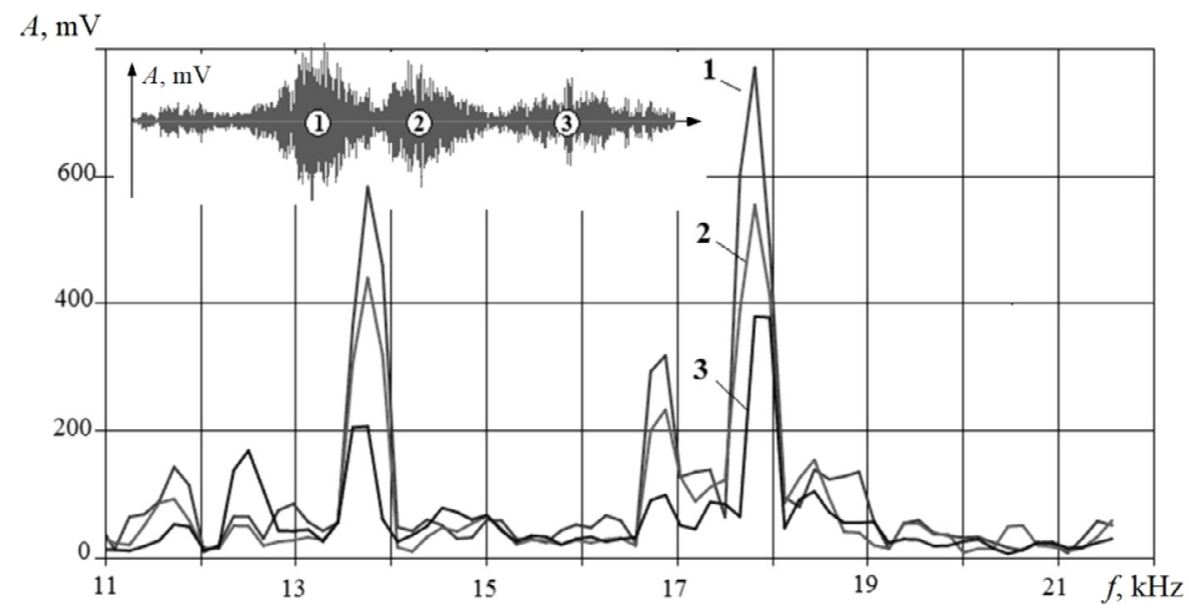

Fig. 9. The comparison of the amplitude spectra of a vibroacoustic signal with a pulse effect on a coated plate for different moments of time corresponding to the maximums of the vibroacoustic signal in an octave of $16 \mathrm{kHz}$ in the range $11-22 \mathrm{kHz}$.

after the 10th ms, there is a sharp increase in amplitude to values that were not previously observed when irradiating steel plates without a deposited film. Its value is more than four times higher than the previously recorded maxima in this frequency range. These facts indicate the occurrence of a process with high vibroacoustic activity after the 10th $\mathrm{ms}$.

Note that the high-frequency vibroacoustic signal in the octave of $32 \mathrm{kHz}$, the maximum effective amplitude of which was observed in the region of $5 \mathrm{~ms}$, differs from its analogues in the irradiation of the uncoated plates (Fig. 8b) by increased amplitude values. Attention is also drawn to the wave-like nature of the signal attenuation, manifested in both octaves. Local maxima were observed at the 15th, 24th, and 35th ms.

Figure 9 shows three vibroacoustic signal spectra in the frequency range $11-22 \mathrm{kHz}$. These spectra were plotted for the intervals located in the region of three maxima in an octave of $16 \mathrm{kHz}$ (the numbers indicate the positions of the sections on the record for spectral analysis).

Figure 10 gives a similar comparison of the spectra, but in the higher frequency range of $24-40 \mathrm{kHz}$. The field in the corner shows the section for recording the vibroacoustic signal for an octave of $32 \mathrm{kHz}$, which denotes the location of the places for spectral analysis. These places corresponded to the local maxima for recording in the $16 \mathrm{kHz}$ octave.

Figures 9 and 10 show that the spectral maxima retain their positions on the frequency axis on all graphs. They suggest that the excitation of vibroacoustic signals occurs mainly at the natural frequencies of the elastic system of the measuring channel. The amplitude at high frequencies decays faster over time.

The process that causes a sharp increase of vibroacoustic signals in octaves of $32 \mathrm{kHz}$ at $5 \mathrm{~ms}$ and $16 \mathrm{kHz}$ at $10 \mathrm{~ms}$ requires a physical explanation, as well as the subsequent wave-like attenuation. 


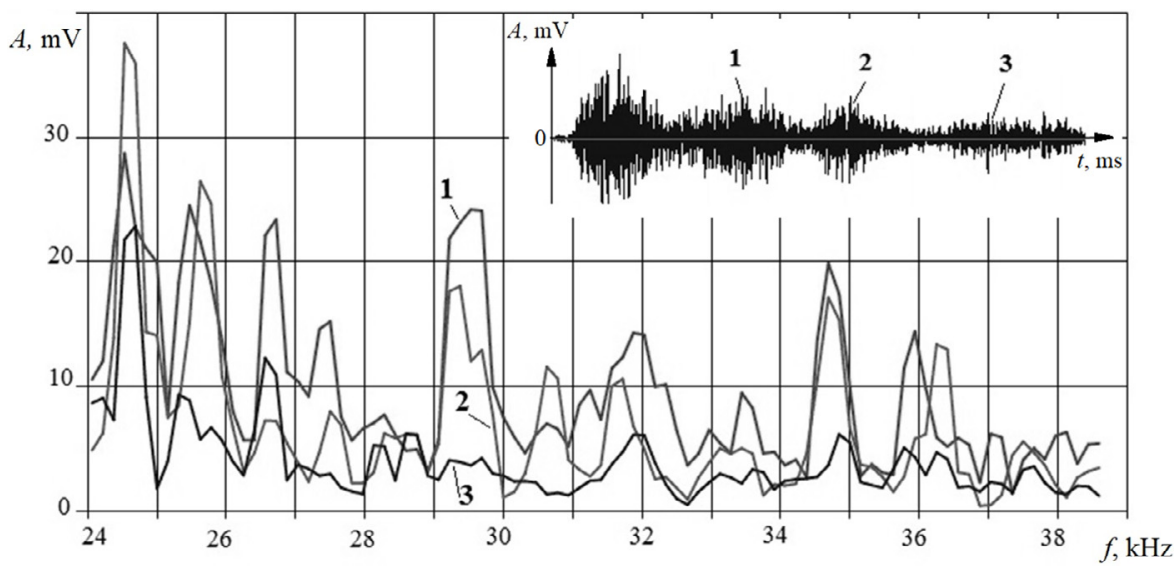

Fig. 10. The comparison of the amplitude spectra of the vibroacoustic signal with a pulse effect on a coated plate for different moments, corresponding to the maxima of the vibroacoustic signal in an octave of $32 \mathrm{kHz}$ in the range of $24-40 \mathrm{kHz}$.

Table 1. The parameters of the surface roughness of the samples after exposure to the electron beam.

\begin{tabular}{llll}
\hline Sample & $R_{\mathrm{Z}}, \mu \mathrm{m}$ & $R_{\mathrm{A}}, \mu \mathrm{m}$ & $S_{\mathrm{A}}, \mu \mathrm{m}$ \\
\hline Original & $1.33 \pm 0.45$ & $0.51 \pm 0.33$ & $0.19 \pm 0.09$ \\
Irradiation, charging voltage $20 \mathrm{kV}$ & $4.02 \pm 1.14$ & $1.18 \pm 0.34$ & $2.35 \pm 0.12$ \\
Nitrated, charging voltage $20 \mathrm{kV}$ & $4.56 \pm 1.22$ & $1.27 \pm 0.36$ & $2.23 \pm 0.10$ \\
Surface alloying, charging voltage $20 \mathrm{kV}$ & $5.60 \pm 0.52$ & $1.49 \pm 0.19$ & $3.28 \pm 0.06$ \\
Surface alloying, charging voltage $22 \mathrm{kV}$ & $9.83 \pm 2.28$ & $3.15 \pm 0.51$ & $5.80 \pm 0.80$ \\
Surface alloying, charging voltage $24 \mathrm{kV}$ & $9.83 \pm 2.10$ & $3.60 \pm 0.73$ & $8.84 \pm 1.01$ \\
\hline
\end{tabular}

It can be assumed that such a behavior of the vibroacoustic signal is associated with martensitic transformation in several stages, caused by the chemical reaction of the formation of the nitride phase based on niobium against the background of shock compression.

The surface structure of the material undergoes noticeable changes. A significant number of small craters form in the areas with changed chemical composition, that is, in the locations of the inclusions. The data on the morphology and topography of the surface indicate that the mechanism of crater formation is thermo-capillary convection [40]. The number of craters decreases with increasing charge stress, which indicates the homogenization of the material in the near-surface layer. However, this increases the surface roughness and undulation parameters (Tab. 1).

Studies $[41,42]$ have shown that the formation of new phases can be accompanied by the generation of highfrequency (about $1 \mathrm{MHz}$ ) acoustic oscillations. The applied equipment did not register such frequencies, but the observed surface relief suggests that the high-frequency mode is also present in the case under consideration. The period of the standing wave frozen on the surface of the samples has a value of $2-8 \mu \mathrm{m}$, which corresponds to the frequency about $0.5-1.5 \mathrm{MHz}$. With an increase in the accelerating voltage, the frequency of such vibration decreases.

The content of the austenitic phase in the near-surface layer drops sharply after the electron-beam alloying operation. If at a charging voltage of $20 \mathrm{kV}$, the ratio of austenite and martensite is approximately 40:60, when it increases to $22-24 \mathrm{kV}$, the amount of residual austenite stabilizes at $10 \%$.

At the same time, in the study of foils from the nearsurface layers of irradiated objects prepared for the transmission electron microscope, the ratio of the fields occupied by $\alpha$ and $\gamma$ phases is approximately the same, which indicates a higher content of residual austenite directly at the surface of the samples (Fig. 11). The grain size of austenite is $3-5 \mu \mathrm{m}$.

Inside the grain, there is a regular cellular structure up to $0.1 \mu \mathrm{m}$ in size. The cells are separated by dislocation lowangle boundaries. Dislocation low-angle boundaries separate the cells. The grain boundaries are stepped, they pass along the borders of the cells. The fine structure of cells on the border with $\alpha$ phase grains is characterized by a high density of flat defects, which can be twins or packing defects, indicating a high level of residual stresses, which can reach $550 \mathrm{MPa}$ [43], leading to plastic deformation in the austenitic grain before polymorphic transformation (Fig. 11d).

The fields occupied by the $\alpha$ phase represent a finegrained structure of the deformation martensite, formed in accordance with the records of the vibroacoustic signal at a time when the irradiated sample has already cooled down in nonequilibrium conditions in the external elastic field. The formation of such martensite is well described by the wave model $[44,45]$, 


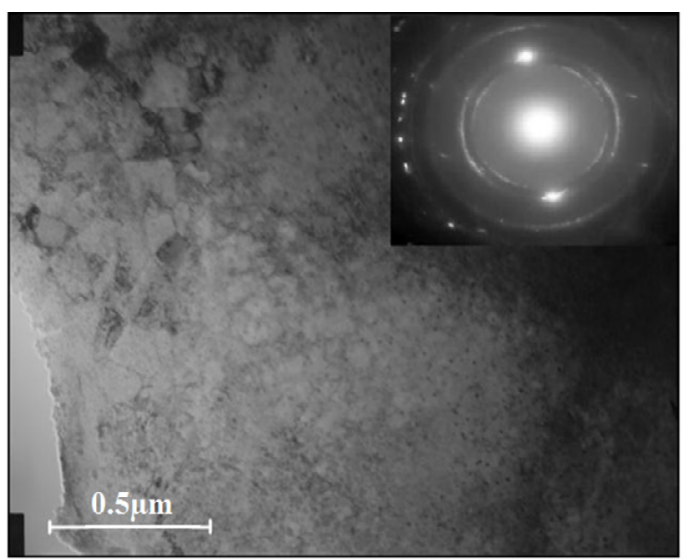

(a)

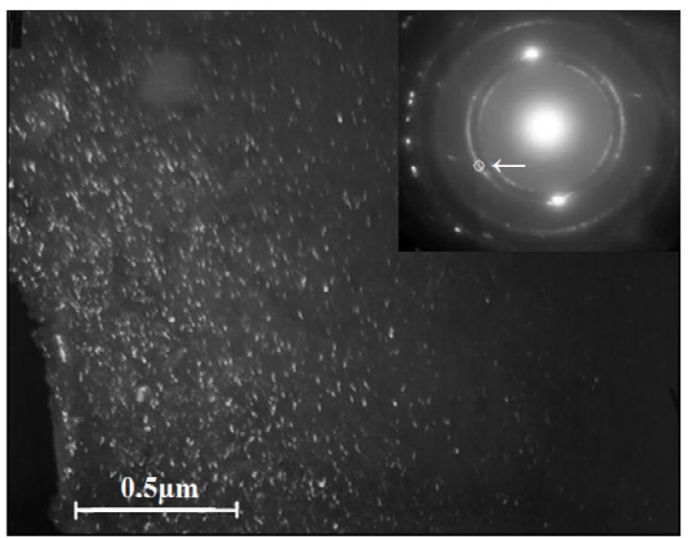

(c)

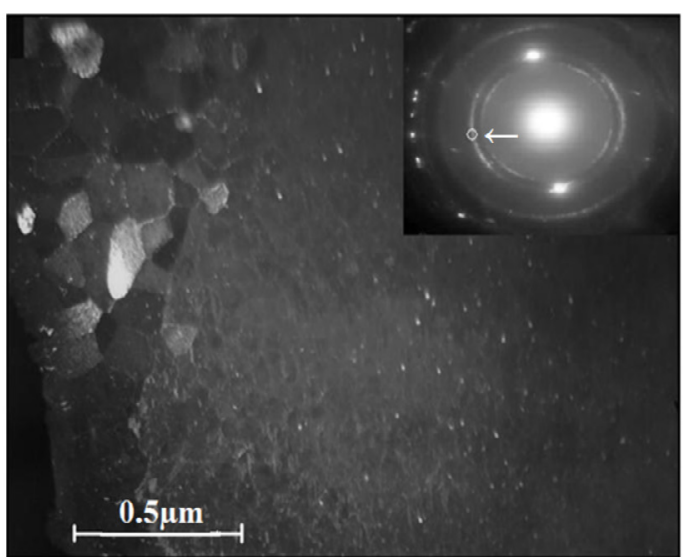

(b)

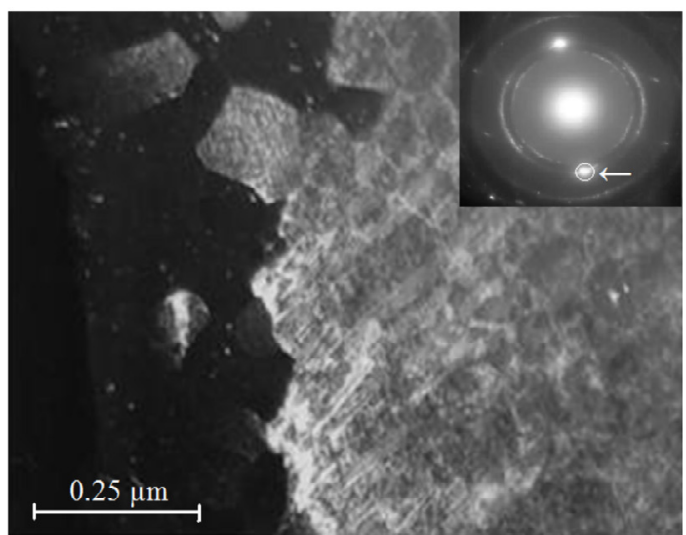

(d)

Fig. 11. Structure of the $08 \mathrm{Cr} 17 \mathrm{Ti}$ steel after nitriding and surface alloying by electron beam $(22 \mathrm{kV})$. The boundary of the $\alpha$ and $\gamma$ phases: (a) a bright field image, (b) a dark field in the $\alpha$ phase reflex, (c) a dark field in the nitride phase reflex, (d) a dark field in the austenite reflex.

which assumes the process of propagation of threshold deformation.

The martensite wave growth model is based on the idea of the new phase growth stage in reconstructive martensitic transformations as a deformation transformation of the lattice propagating in the wave mode. It assumes that the transition to a new structural state is associated with overcoming a certain energy barrier and becomes possible if the level of deformation exceeds a certain threshold, which in our case is achieved approximately $10 \mathrm{~ms}$ after the operational pulse.

The restructuring of the austenite lattice is accompanied by the release of heat and an abrupt change in volume. A growing martensite crystal, starting from the moment of nucleation, has thermal, electrical, and mechanical effects on the $\gamma-\alpha$ interphase region, causing its deviation from the equilibrium state. A nonequilibrium region can be considered as an active medium capable of generating or amplifying waves causing its change. It is a positive feedback mechanism that converts a part of the energy released in the process of transformation into the energy of displacement of atoms, which, in turn, can cause a new wave of martensitic transformation, which could be observed during the above experiments.

A similar change in the morphology of martensite crystals formed under the influence of deformation was considered in some articles [46-50].

The size of the martensitic grain is consistent with the size of the cells in the austenitic grain and is $0.1-0.3 \mu \mathrm{m}$. However, there is a nanostructure with a grain size of up to $50 \mathrm{~nm}$ in some places. Moreover, a more significant variation in grain size is typical for objects processed at a voltage of $24 \mathrm{kV}$ (Fig. 12). In the body of austenite grains, precipitates of nitride phases are observed, mainly along dislocation cell boundaries and martensite grain boundaries as hafnium nitride HfN and niobium nitrides $\mathrm{NbN}$ and $\mathrm{Nb}_{4} \mathrm{~N}_{5}$ (Fig. 11b). It is probably due to a manifestation of structural heredity. The transformation is reversible. Under repeated exposure to an electron beam, the behavior of the vibroacoustic signal is repeated. At the same time, it is unlikely that the released refractory nitride phases will be dissolved, since the heating of the sample surface will be limited by the evaporation temperature of the iron base. 


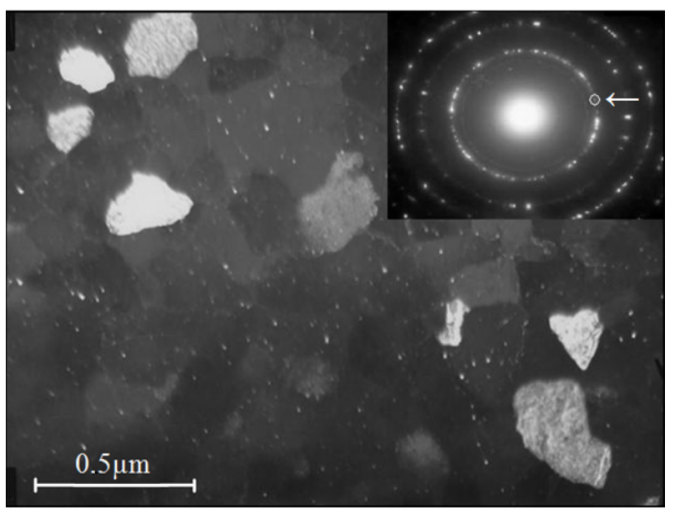

(a)

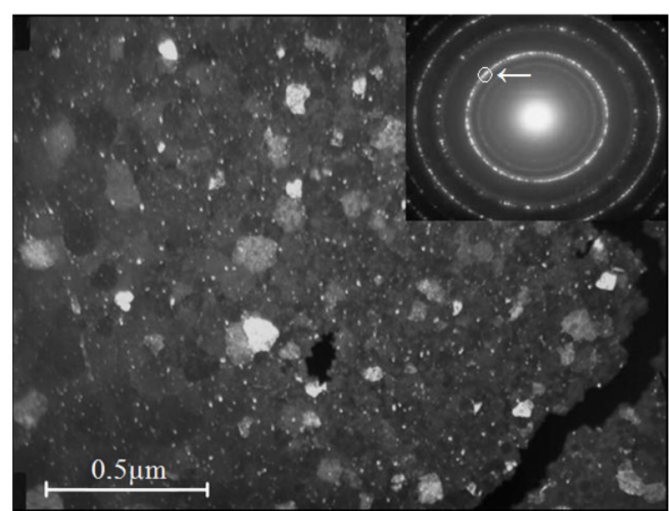

(b)

Fig. 12. Deformation martensite on the surface of the sample of nitrated steel 08Cr17Ti after the treatment with LEHCEB at a charging voltage of $24 \mathrm{kV}$, dark fields in the $\alpha$-phase reflex: (a) area with grain size from 0.1 to $0.5 \mu \mathrm{m}$, (b) domain with nanoscale martensite grains.

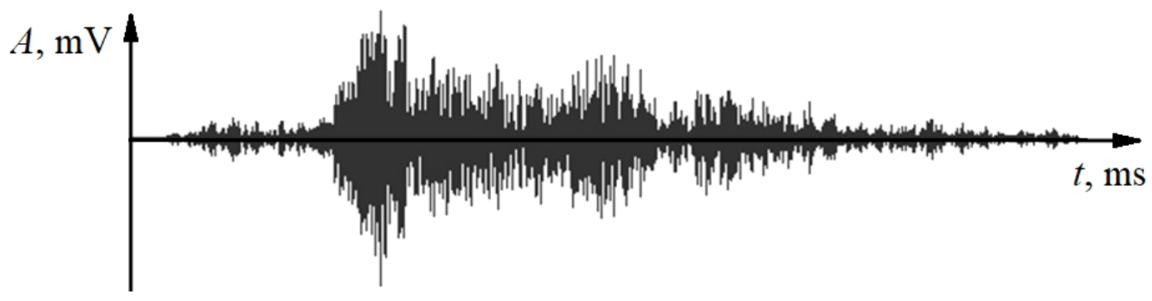

(a)

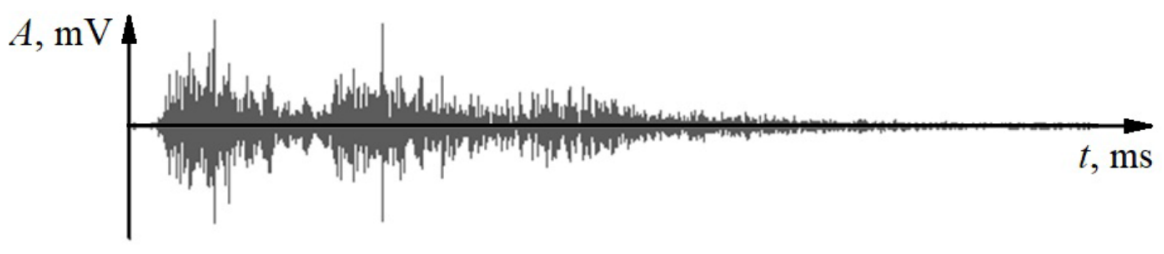

(b)

Fig. 13. An example of recording the vibroacoustic signal in two frequency ranges when irradiated with a nitrated steel plate coated with NbHfTi alloy: (a) signal in the range $11-22 \mathrm{kHz}$; (b) signal in the range $28-40 \mathrm{kHz}$.

\section{Discussion}

The vibroacoustic signals accompanying the processes in materials subjected to electron-beam action have a complex spectrum that varies with time. A certain deterministic algorithm of vibroacoustic signal processing is required [51], which allows having real-time information about the quality of the obtained results in order to effectively control the results of irradiation of various materials in an automated mode. It may be enough to have a limited set of diagnostic parameters, the digital values of which allow judging the results of the technological process. However, such a set of parameters should have sufficient resolution to separate all the situations that accompany the process. Due to the diversity of the irradiated objects and the corresponding consequences, the minimum required set of diagnostic parameters may be different for each case. The search for such a minimum (optimal) set, sufficient to monitor a particular process, is a scientific task.

It is possible to consider an example of finding diagnostic signs for an above-considered case. Figure 13 shows an example of records of a vibroacoustic signal in different frequency ranges: The records of a vibroacoustic signal are the records of the damped vibrations, but the form of damping is quite complex. It is modulated by a lowfrequency component that gives the vibroacoustic signal a characteristic shape. 


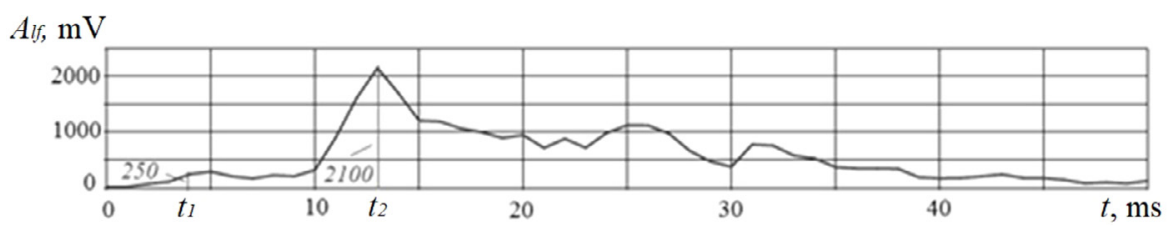

(a)

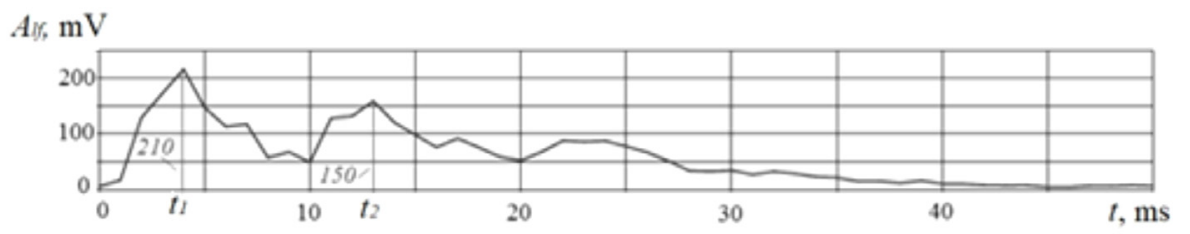

(b)

Fig. 14. The envelope of the amplitudes of the vibroacoustic signal presented: (a) the amplitude of low-frequency spectra in the range of $11-22 \mathrm{kHz}$; (b) the amplitude of high-frequency spectra in the range of $28-40 \mathrm{kHz}$.

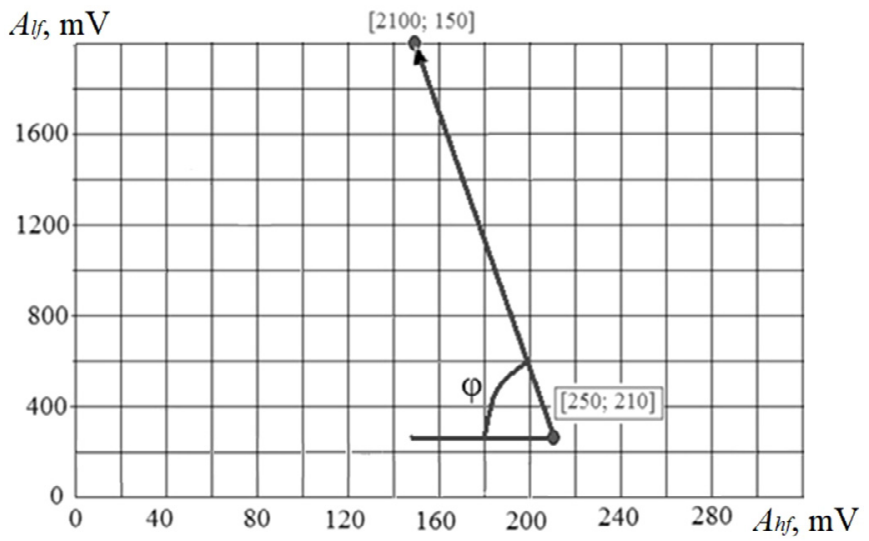

Fig. 15. The graphical representation of changes in the envelopes of the vibroacoustic signal, shown in Figure 13 (lowfrequency component $-A_{\mathrm{lf}}$, high-frequency component $-A_{\mathrm{hf}}$ ).

Although the presented frequency ranges are quite close to each other, the shape of the signals varies considerably. It is advisable to present it in the form of an envelope for simplification of the processing of the original signal. Hence, the entire signal is divided into time intervals and for each of them, the mean square value of the signal is determined. The totality of the obtained values gives an envelope. If the maximum value of the amplitude is selected on each segment of the partition, then the peak envelope can be received. For splitting into segments, the length of the intervals is very important. Too small intervals leave a lot of unnecessary details; too long intervals can lose informative components. Figure 14 presents the mean square envelopes of the vibroacoustic signal shown in Figure 13. The length of the split segment is $1 \mathrm{~ms}$.

A characteristic feature of vibroacoustic signals in the high-frequency and low-frequency ranges accompanying the irradiation of coated nitrated steel plates was the presence of peaks in their envelopes that did not coincide in time. Figure 14 demonstrates that the first maximum occurs at time $t_{1}$ at the high-frequency component (Fig. 14b). In the considered case, the amplitude of the high-frequency component $A_{\mathrm{hf}}$ at time $t_{1}$ is $210 \mathrm{mV}$. Accordingly, at the same time $t_{1}$, the amplitude $A_{\mathrm{lf}}$ is equal to $250 \mathrm{mV}$. A point with coordinates $[250 ; 210]$ on the plane with the coordinates $\left(A_{\mathrm{hf}}, A_{\mathrm{lf}}\right)$ can be drawn using these data. The second point can be constructed similarly for the maximum at time $t_{2}$ for the low-frequency envelope (Fig. 14a). At the time $t_{2}$, $A_{\mathrm{lf}}=2100 \mathrm{mV}, A_{\mathrm{hf}}=150 \mathrm{mV}$, and the second point will have the coordinates $[2100 ; 150]$. Figure 15 shows an example of drawing the above points, the coordinates of which are indicated next to them. A straight line can connect the two obtained points. The arrow at the end of the vector shows the appearance of these points in time.

However, the vector image of the results though allows distinguishing changes in the character of the vibroacoustic signal but is somewhat cumbersome. Its image with a large amount of data may be difficult to read. It is possible to simplify the graphi image of the results of experiments further and present the results of experiments in the coordinates $\left(A_{\mathrm{lf}}, t g \varphi\right)$. The angle $\varphi$ is the angle of inclination of the vector relative to the $x$-axis (Fig. 15).

Figure 16a depicts the vectors belonging to three series of experiments with $08 \mathrm{Cr} 17 \mathrm{Ti}$ steel plates: in the initial state, after ion nitriding and after surface alloying. It can be seen that the parameters of the vectors unambiguously allow distinguishing a series of tests. It can be seen that the vectors differ in the angle of inclination relative to the coordinate axes and in the position of the top point corresponding to the time $t_{2}$ and group according to their series, forming clusters that are distinguishable in these coordinates. Figure 16b shows the image transformation of Figure 16a, where the modulus of the slope of the vectors $\varphi$ is presented instead of the parameter $A_{\mathrm{hf}}$. In these coordinates, the delimitation of the clusters survives, and the image of the results has become more familiar. 


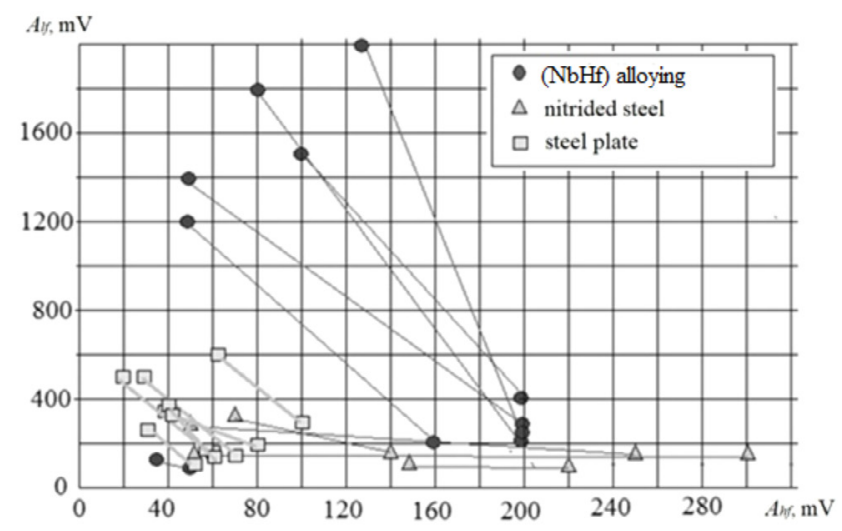

(a)

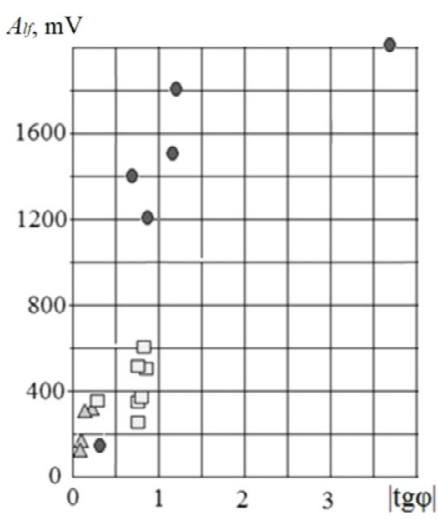

(b)

Fig. 16. Graphic representation of changes in the surface treatment of steel using LEHCEB according to the analysis of vibroacoustic vibrations: (a) the vector image of the results; (b) the presentation of results in the coordinates $\left(A_{\mathrm{lf}}, \operatorname{tg} \varphi\right)\left(A_{\mathrm{lf}}-\right.$ low-frequency component, $A_{\mathrm{hf}}-$ high-frequency component, $\varphi-$ the angle of vector inclination (Fig. 15)).

The exception is one point from a series of experiments using surface alloying, located in a cluster of the original irradiated sample. This point corresponds to the first impulse in the series. For many initial pulses, there is typically a sharp difference from subsequent results, which can be attributed to the adsorption of various kinds of impurities on the surface of the coating. Starting from the second or third pulse, the treatment, as a rule, is successful. The data of vibroacoustic analysis confirm it.

In a number of technologies of surface hardening of products, surface alloying, including pulsed electron beam, begins to occupy an increasingly prominent place [52]. This technology opens up new opportunities for the use of existing materials and the development of new ones. When developing the technology of such processing, the use of vibroacoustic monitoring allows to study the kinetics of processes taking place in different materials as a result of powerful and short, of the order of several microseconds, thermal effects.

\section{Conclusions}

The monitoring of the vibroacoustic signal allows observing the course of transformations occurring during surface electron-beam alloying and judging the sufficiency of the power of the supplied pulses of electron radiation.

If we track changes in the effective value of the vibroacoustic signal, we can choose the rational modes of irradiation during the electron-beam surface alloying, suggesting, on the one hand, the maximum possible supply of power, while on the other, the limitations caused by the possibility of evaporation of the predeposited film with alloying components. In this case, the rational value of the charging voltage was $22 \mathrm{kV}$, which corresponds to the energy density $5.2 \mathrm{~J} / \mathrm{cm}^{2}$.

The surface alloying processes, arising from the interaction of LEHCEB with nitrated ferritic stainless steel, consist of the following events:
- after the initial growth of the vibroacoustic signal in an octave of $16 \mathrm{kHz}$ for $5-7 \mathrm{~ms}$, a slight decrease in amplitude is observed;

- after $10 \mathrm{~ms}$ begins a sharp rise in the amplitude of the vibroacoustic signal in an octave of $16 \mathrm{kHz}$, exceeding the initial value by three to four times;

- local amplitude rise is repeated two to three more times with a period of about $10 \mathrm{~ms}$, but at lower extreme values; - herewith, the maximum of the vibroacoustic signal in an octave of $32 \mathrm{kHz}$ is observed during the initial growth of the vibroacoustic signal in an octave of $16 \mathrm{kHz}$, the local maxima of the amplitude are also observed in this octave, coinciding in time with the maxima in the octave of $16 \mathrm{kHz}$ with a decreasing amplitude.

This behavior of the vibroacoustic signals indicates the processes associated with the change in the structure of the near-surface layer subjected to the doping operation. In particular, there is a connection between the reaction of the formation of deformation martensite and the corresponding vibroacoustic signal, which allows us to describe the kinetics of this transformation.

The implementation of vibroacoustic monitoring of the process of electron-beam surface alloying for different combinations of irradiated materials may require different combinations of the diagnostic parameters of vibroacoustic signals.

Acknowledgments. The financial support provided by the Ministry of Education and Science of the Russian Federation, in the framework of the state task in the field of scientific activity of MSTU "STANKIN" (No.11.1817.2017/4.6). The work is carried out on the equipment of the Center of collective use of MSTU STANKIN.

\section{References}

[1] A.B. Markov, E.V. Yakovlev, V.I. Petrov, Formation of surface alloys with a low-energy high-current electron beam 
for improving high-voltage hold-off of copper electrodes, IEEE Trans. Plasma Sci. 41 (2013) 2177-2182.

[2] S.V. Fedorov, G.V. Oganyan, Special features of electronbeam alloying of replaceable polyhedral hard-alloy plates under a complex surface treatment, Metal Sci. Heat Treat. 57 (2016) 620-624.

[3] S. Fedorov, Min Htet Swe, Wear of carbide inserts with complex surface treatment when milling nickel alloy, Mechanics \& Industry 18 (2017) 710.

[4] S.V. Fedorov, S.V. Aleshin, M.H. Swe, Comprehensive surface treatment of high speed steel tool, Mechanics \& Industry 18 (2017) 711.

[5] S.V. Fedorov, M.H. Swe, Refractory phases synthesis at the surface microalloying using a wide aperture electron beam, J. Phys. Conf. Series 830 (2017) 012076.

[6] D.S. Nazarov, V.P. Rotshtein, D.I. Proskurovsky, A.B. Markov, Pulsed electron-beam technology for surface modification of metallic materials, J. Vac. Sci. Technol. 16 (1998) 2480-2488.

[7] M.I. Dvornik, A.V. Zaitsev, Destruction of hard alloy VK8 with termodom, Mech. Adv. Mater. Struct. 15 (2009) 52-58.

[8] O.A. Capetolo, V.S. Zanuto, G.V.B. Lukasievicz, L.C. Malacarne, Generation and detection of thermoelastic waves in metals by a photothermal mirror method, Appl. Phys. Lett. 109 (2016) 1.91908.

[9] X. Wang, X. Xu, Thermoelastic wave induced by pulsed laser heating, Appl. Phys. A 73 (2001) 107-114.

[10] V.V. Uglov, N.N. Kowal, A.K. Kuleshov, Y.F. Ivanov, A.D. Interest, E.A. Soldatenko, Structure-phase transformation in surface layers of hard alloy as a result of action of high current electron beams, Surf. X-ray Synch. Neutron Stud. 4 (2011) 50-58.

[11] T.V. Vahniy, G.A. Vershinin, G.I. Gering, N.I. Pischasov, Enhanced mass transfer under pulsed effects on metal systems, Bull. Omsk Univ. 3 (2003) 28-30.

[12] G.A. Vershinin, V.A. Volkov, G.L. Buchbinder, G.I. Gering, Local nonequilibrium mass transfer in a two-component system under external pulsed irradiation with energy fluxes, J. Surf. Investig. 8 (2014) 712-716.

[13] N.A. Pischasov, A.V. Nikolaev, Modification of the structure and properties of hard alloys of WC-Co system by highcurrent charged particle beams, Bull. Omsk Univ. 2 (1996) $39-43$.

[14] S. Konovalov, X. Chen, V. Sarychev, S. Nevskii, V. Gromov, M. Trtica, Mathematical modeling of the concentrated energy flow effect on metallic materials, Metals 7 (2017) 4.

[15] G.E. Ozur, D.I. Proskurovsky, V.P. Rotshtein, A.B. Markov, Production and application of low-energy, high-current electron beams, Laser Part. Beams 21 (2003) 157-174.

[16] S.N. Grigoriev, V.A. Sinopalnikov, M.V. Tereshin, Control of parameters of the cutting process on the basis of diagnostics of the machine tool and workpiece, Meas. Techn. 55 (2012) 555-558.

[17] S.N. Grigoriev, M.P. Kozochkin, E. Yu. Kropotkina, Study of wire tool-electrode behavior during electrical discharge machining by vibroacoustic monitoring, Mechanics \& Industry 17 (2016) 717.

[18] S.N. Grigoriev, M.P. Kozochkin, F.S. Sabirov, Diagnostic systems as basis for technological improvement, in: K. Wegener (Ed.), 5th CIRP International Conference on High Performance Cutting, Zurich, Switzerland, June 4-7, 2012, Elsevier, New York, 2012.
[19] S.N. Grigoriev, V.D. Gurin, M.A. Volosova, Development of residual cutting tool life prediction algorithm by processing on CNC machine tool, Materialwiss. Werksttech 44 (2013) 790-796.

[20] N.A. Semashko, V.I. Shport, B.N. Marin, Acoustic emission in experimental materials science, Mechanical Engineering, Moscow, 2002

[21] F. Su, T. Li, X. Pan, M. Miao, Acoustic emission responses of three typical metals during plastic and creep deformations, Exp. Tech. 42 (2018) 685-691.

[22] C. Barile, C. Casavola, G. Pappalettera, C. Pappalettere, Acoustic emission analysis of aluminum specimen subjected to laser annealing, Residual Stress Thermomech. Infrared Imaging Hybrid Tech. Inverse Problems 8 (2014) 309-315.

[23] Z. Han, H. Luo, Y. Zhang, J. Cao, Effects of micro-structure on fatigue crack propagation and acoustic emission behaviors in a micro-alloyed steel, Mater. Sci. Eng. A 559 (2013) $534-542$.

[24] C. Barile, C. Casavola, G. Pappalettera, C. Pappalettere, Hybrid thermography and acoustic emission testing of fatigue crack propagation in aluminum samples, Fract. Fatigue Failure Damage Evol. 5 (2015) 247-252.

[25] P. Mazal, F. Vlasic, V. Koula, Use of acoustic emission method for identification of fatigue micro-cracks creation, Procedia Eng. 133 (2015) 379-388.

[26] A.N. Smirnov, Generation of acoustic oscillations in chemical reactions and physicochemical processes, Russ. Chem. J. 45 (2001) 29-33.

[27] S.N. Zadumkin, Kh.B. Khokonov, H.B. Chakarov, Acoustic effect of crystallization and melting of the substance, JETP 68 (1975) 1315-1320.

[28] M. Łazarska, T.Z. Wozniak, Z. Ranachowski, A. Trafarski, G. Domek, Analysis of acoustic emission signals at austempering of steels using neural networks, Met. Mater. Int. 23 (2017) 426-433.

[29] A. Mostavi, N. Kamali, N. Tehrani, S.W. Chi, D. Ozevin, J.E. Indacochea, Wavelet based harmonics decomposition of ultrasonic signal in assessment of plastic strain in aluminum, Measurement 106 (2017) 66-78.

[30] H.N.G. Wadley, C.B. Scruby, J.H. Speake, Acoustic emission for physical examination of metals, Met. Rev. 25 (1980) 41-64.

[31] A.B. Markov, A.V. Mikov, G.E. Ozur, A.G. Padej, Installation of RITM-SP for the formation of surface alloys, Instrum. Exp. Tech. 6 (2011) 122-126.

[32] M.H. Ras, P.C. Pistorius, Possible mechanisms for the improvement by vanadium of the pitting corrosion resistance of $18 \%$ chromium ferritic stainless steel, Corros. Sci. 44 (2002) 2479-2490.

[33] R. Merello, F.J. Botana, J. Botella, M.V. Matres, M. Marcos, Influence of chemical composition on the pitting corrosion resistance of non-standard low-Ni high-Mn-N duplex stainless steels, Corros. Sci. 4 (2003) 909-921.

[34] S.N. Grigoriev, A.S. Metel, S.V. Fedorov, Modification of the structure and properties of high-speed steel by combined vacuum-plasma treatment, Metal Sci. Heat Treat. 54 (2012) $8-12$.

[35] A. Metel, S. Grigoriev, Yu. Melnik, Cutting tools nitriding in plasma produced by a fast neutral molecule, Jpn. J. Appl. Phys. 50 (2011) 08JG04.

[36] A.N. Ivanov, E.I. Fomicheva, E.V. Shelekhov, Application of a sliding beam for the study of surface layers on a generalpurpose X-ray diffractometer, Plant Lab. 12 (1980) 41-47. 
[37] N.A. Kochinev, F.S. Sabirov F.S., M.P. Kozochkin, The certificate of state registration of computer programs No. 2009613214 (RU), 2009.

[38] M.P. Kozochkin, N.A. Kochinev, F.S. Sabirov, Diagnostics and monitoring of complex production processes using measurement of vibration-acoustic signals, Meas. Tech. 49 (2006) 672-678.

[39] M.P. Kozochkin, A.N. Porvatov, Effect of adhesion bonds in friction contact on vibroacoustic signal and auto-oscillations, J. Friction Wear 35 (2014) 389-395.

[40] A.B. Markov, L.L. Meisner, E.V. Yakovlev, Crater formation on the surface of stainless steel and titanium nickelide irradiated with low-energy electron beam: morphology and topography, proceedings of higher educational institutions, Physics 58 (2015) 173-177.

[41] A.I. Kirdyashkin, R.M. Gabbassov, Yu.M. Maksimova, V.G. Salamatova, Acoustic emission during self-propagating hightemperature synthesis, Combust. Explos. Shock Waves 49 (2013) 676-681.

[42] S.I. Kudryashov, K. Lyon, S.D. Allen, Parametric generation of multimegahertz acoustic oscillations in laser-generated multibubble system in bulk water, Appl. Phys. Lett 88 (2006) 214105.

[43] L.L. Meisner, A.I. Lotkov, M.G. Ostapenko, E. Yu. Gudimova, X-ray diffraction study of residual elastic stress and microstructure of near-surface layers in nickel-titanium alloy irradiated with low-energy high-current electron beams, Appl. Surf. Sci. 280 (2013) 398-404.

[44] M.P. Kashchenko, Wave model of martensite growth during $\gamma-\alpha$ transformation in iron-based alloys, Scientific center "Regular and chaotic dynamics", Izhevsk Institute of computer research, Moscow-Izhevsk, 2010.
[45] M.P. Kashchenko, A.G. Semenovih, V.G. Chashchina, Cryston model of $\alpha$ strain-induced martensite, J. Phys. 112 (2003) 147-150.

[46] M. Shaira, N. Godin, P. Guy, L. Vanel, J. Courbon, Evaluation of the strain-induced martensitic transformation by acoustic emission monitoring in $304 \mathrm{~L}$ austenitic stainless steel: identification of the AE signature of the martensitic transformation and power-law statistics, Mater. Sci. Eng. A 492 (2008) 392-399.

[47] R. Khamedi, A Fallahi, H. Zoghi, The influence of morphology and volume fraction of martensite on AE signals during tensile loading of dual-phase steels, Int. J. Recent Trends Eng. 1 (2009) 30-34.

[48] E.H. Ahmad, T. Manzoor, M.M.A. Ziai, N. Hussain, Effect of martensite morphology on tensile deformation of dual-phase steel, J. Mater. Eng. Perform. 21 (2011) 1-6.

[49] H. Ohtsuka, K. Takashima, G.B. Olson, Nonthermoelastic and thermoelastic martensitic transformation behavior characterized by acoustic emission in an $\mathrm{Fe}-\mathrm{Pt}$ alloy, DOI: $10.1557 /$ PROC-459-407

[50] L. Morsdorf, O. Jeannin, D. Barbier, M. Mitsuhara, D. Raabe, C.C. Tasan, Multiple mechanisms of lath martensite plasticity, Acta Mater. 121 (2016) 202-214.

[51] T. Barszcz, Decomposition of vibration signals into deterministic and nondeterministic components and its capabilities of fault detection and identification, Int. J. Appl. Math. Comput. Sci. 19 (2009) 327-335.

[52] J. Duan, Y. Huang, R. Zhang, L. Wan, H. Li, J. Liu, Status and development of surface alloying by electron beam, Proceedings of the International Conference on Materials, Environmental and Biological Engineering (MEBE 2015) Guilin, China, 2015, pp. 646-649.

Cite this article as: S.V. Fedorov, M.P. Kozochkin, M.M. Stebulyanin, Control of the surface electron-beam alloying process by vibration monitoring, Mechanics \& Industry 19, 702 (2018) 